\title{
The Exploration and Analysis of College Students' Emotional Experience Practice Based on Mask Art \\ Ying Zhao
}

Department of Art and Design, Academy of Fine Arts, Yunnan Normal University,

Chenggong, ChinaKunming, Yunnan, China

email: 893829008@qq.com

Key Word: mask art, emotional experiences, emotional intelligence.

Abstract. College students' level of emotional intelligence will directly affect their ability of academic, interpersonal communication and social adaptability, etc. This article aims to make college students to perform the practice of emotional experience by guiding them to make their own "emotional masks", to courage college students to face their emotional problems in a right way and to develop their emotional management creatively so as to improve their emotional intelligence. The practical cases in this article are innovation and breakthrough across education, art and psychology.

\section{基于面具艺术的大学生情绪体验实践探析 \\ 赵茕 \\ 云南师范大学美术学院艺术设计系, 呈贡, 昆明, 云南, 中国 email: 893829008@qq.com}

关键词：面具艺术; 情绪体验;情绪智力

中文摘要. 大学生的情绪智力高低会直接影响大学生的学业、人际交往和社会适应等能力。本 文是通过引导大学生制作自己的 “情绪面具” 从而进行情绪体验的实践, 鼓励大学生正确面 对情绪问题、创造性的发展情绪管理的方法来提高情绪智力。本文的实践案例是跨教育、艺 术与心理学的创新和突破。

\section{1. 引言}

艺术本身就具有治愈功能。本文通过引导大学生制作 “情绪面具” ，帮助大学生积极的 进行情绪体验、了解情绪背后的动机与需求、创造性的发展情绪管理的办法等方面来协助大 学生的提高情绪智力。研究是跨教育、艺术、心理学三个领域的创新性实践。

\section{2. 面具}

\section{1 面具的起源}

面具起源可以从旧石器时代追溯到新石器时代, 不同地域的民族都不约而同的创造了面 具, 从狩猎、图腾崇拜、部落战争、巫术仪式、文化活动等的进程来看, 这个文化现象的出 现是有必然性的。我国古代把面具称为假面、鬼头、套头、脸子、面壳、鬼脸等。不少的国 家和地区，面具的应用仍然非常广泛，例如：中国的萨满面具、藏巴面具（图1,白面老 人)、傩面具（图2）、社戏面具; 日本的伎乐面、舞乐面、行道面、追傩面、能乐面（图 
3）; 韩国的河回面具; 泰国的鲁士面具、筇面具、鬼面具; 爪洼的恶魔面具; 意大利的嘉 年华面具（图6）; 美洲、非洲的原始图腾崇拜面具（图5）、埃及法老面具等。从历史学与 考古学的角度看, 面具发展至今, 已成为一个符号化的元素。

\section{2 面具的造型分类}

面具分作：半面面具（图6）和全面面具（图1、图2、图3、图4、图5），多层面具、动 物断腭面具、动物吊腭面具等。

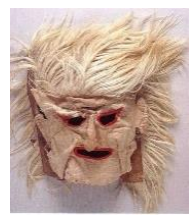

图1

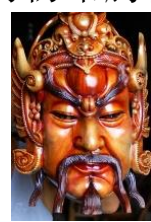

图2

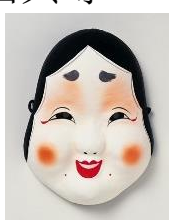

图3

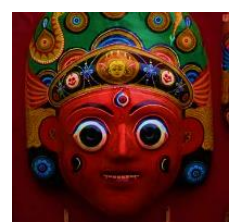

图4

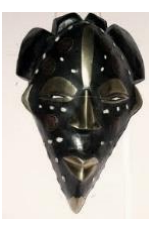

图5

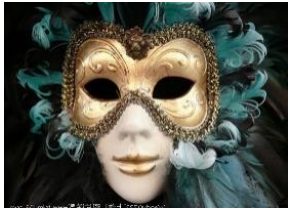

图6

\section{3. 情绪}

\section{1 情绪的种类}

现代心理学将情绪分作基本情绪（原始情绪）和复合情绪, 基本情绪包含5种：喜、怒、 哀、惧、忧, 其中正性情绪是喜, 负性情绪是怒、哀、惧、忧。复合情绪即是基础情绪派生出 来的综合情绪, 例如: 喜爱、怨恨、烦恼、忧愁、抑郁、自尊、自卑、骄傲、委屈、着急、心 慌、差愧、懊悔、抱兼、惊奇、警觉、疑惑、感激、敬佩、同情、思念、轻䒼、羡慕、满意、 失望、孤独、烦躁、惊喜、苦闷、苦恼、纳闷、受宠若惊、欣慰、差怯、忧伤等。

\section{2 情绪智力}

丹尼尔・戈尔曼1995年在其著作《情绪智力》中，定义了情绪智力的概念： “控制情绪冲 动、理解他人的内部情感以及处理人际关系的能力”, 包含五个部分: 认识自己的情绪; 妥 善管理自己的情绪; 自我激励; 对他人情绪的理解及人际关系的管理。情绪智力的意义是:

一、了解自己, 认识情绪背后的需求与动机, 不压抑情绪及正面的处理负性情绪。二、有共 情的能力。共情是指个体识别他人情绪状态, 设身处地理解他人而产生相应的情感反应和体 验, 并准确反馈给对方的能力。三、积极正向的处理人际关系, 建立良好的伙伴关系、能进 行团体协作。

\section{3 情绪体验与艺术}

情绪体验是情绪的一个重要组成部分，指个体如何体验自己的情绪。艺术创作很大一部 分是源于情绪, 反之, 作品又影响着情绪。例如米开朗基罗在创作 “大卫” 时塑造的不仅是 一尊雕像, 而是对《圣经》中的这个重要人物注入了巨大的情感。如罗丹的雕塑 “思考

者”, 取自《神曲》中的《地狱之门》。思想者象征着但丁: “他默默凝视着下面被洪水吞 噬的苦难深重的人们。他爱人类, 难以对那些罪人作出最后判决, 他深怀同情, 陷入极大痛 苦和永恒的沉思之中。

\section{4. 情绪面具}

中国古话说: “不以物喜，不以已悲”，可理解为: 不要在欢乐和悲伤的事情上有情绪 反应, 要内玫的让别人都认为 “我” 很淡定。但正确的面对、了解与理解自己的情绪, 不排 斥、不压抑，正向的处理负性情绪，才能更好的发展个体的情绪智力。 


\section{1 主题设定}

本文通过引导大学生制作自己的情绪面具，将情绪体验投射到面具上，进一步提高情绪 智力的水平。本课题的具体做法：一、选择自己最想表达的情绪词汇：例如：快乐、愤怒、悲 伤、悲痛、压抑、无奈、嫉妒等，可是一个或多个词汇; 二、将情绪词汇应用在一个面具艺术 的制作中, 为作品命名, 面具材料不限（木、布、压克力、金属、玻璃、纤维、陶土、石膏、 纸、贝壳、蛋壳、植物、皮、动物皮毛等），可应用肌理装饰; 三、形式: 半面面具、全面 面具任选其一; 四、应用色彩的象征的表现手法。

\section{2 大学生情绪体验探析}

图1: “老了的自己”。“应用了暖色调, 表情看着挺搞笑, 表达一种失落或受伤的情绪”。 图2: “恐惧、哀号、压抑、破碎”。图3-1、3-2: “家暴”，“正面很悲伤，因为小时候有 一次比较严重的家暴, 然后导致手指受伤, 还去医院缝了针, 所以面具表面有个创可贴, 还 有眼睛旁边 “哭的支离破碎的蛋壳” ”, 嘴上缝的线代表一个人做错事的时候, 连呼吸都是 错。背面是阴暗的，用墨水泼成粗的线条，代表无尽的黑暗和无法弥补的疼痛“。图4: “悲”, 悲到喘不上气，压抑着自己的情绪。图5: “悲伤、难过”, “面具正面是用淡淡的浅紫色做 成的脸, 表达了温和, 平静。背面是用碎玻璃渣拼成的脸, 突显内心的悲伤。表达在某些环 境、某些时间、某些事情中即使你很不满、很难过却也要强颜欢笑 “。图6- “恐惧”，“我想 以恐怖的面具来展示自己的内心所想, 带给别人恐怖的感觉让我觉得比较有力量”。图7: “愤 怒”，“心里充满了愤怒又没有地方说，心里乱的就像麻一样的 “。图8: “禁言”，“对于 这个人人都是一脸堆笑的年代, 谁都说着奉承话, 我的思路就是：若把口舌禁闭，兴许人们 能从我的眼睛里看到真正的内心。于是做了这个 “言禁” 面具, 是表达对现实不满的失望和 无奈 “。图9: “两面”, “人们的生活中总是会有两种种情绪: 一种是我们经常要显示出来 的快乐、高兴、乐观、美好、阳光, 来面对生活和人们, 所以面具的一边是多彩的、暖色的。 另一种是不常显示出来的阴暗的一面：伤心、难过、恐惧不安, 所以用冷色来表达, 就算是 难过、讨厌, 也要面对”。图10: “重感冒”。“负面情绪就像得了重感冒一样, 等 “烧退 了, 那就挺好的了 “。图11：“纠结”，“是对于前途的迷茫和苦恼，表达的基本就是心情不 好、烦躁, 很多的纸扭成的线表达心里的纠结和心情的复杂”。图12: “快乐”, “小丑咧嘴 的样子最能带给人欢笑了, 橙色是欢乐的象征”。

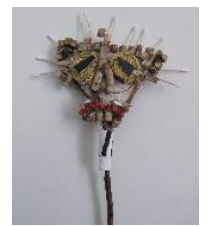

图1

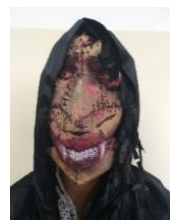

图6

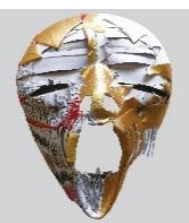

图2

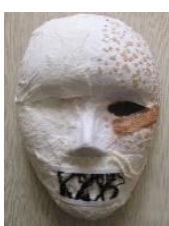

图3-1

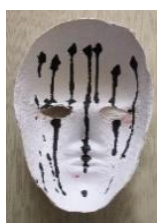

图3-2

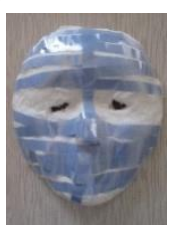

图4

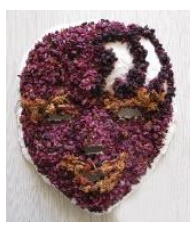

图5-1

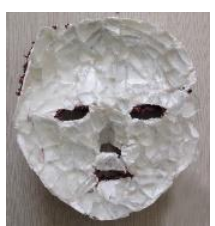

图5-2

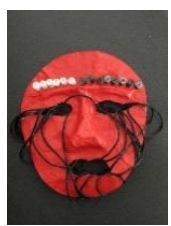

图7

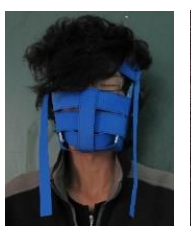

图8

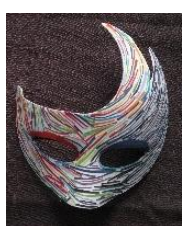

图9

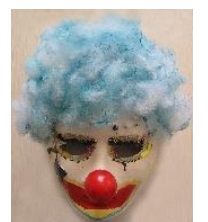

图10

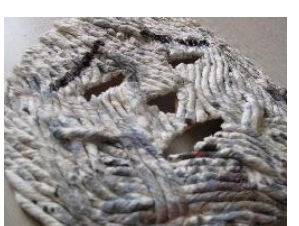

图11

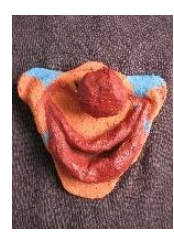

图12

大学生情绪问题解决：一、情绪体验：分析基础、复合情绪, 确认情绪无对错之分, 不 压抑、不排斥情绪。二、情绪处理: 创造符合自己的情绪管理办法。如应用艺术的方法（制 作情绪面具、雕塑、绘画等。) 倾诉、听音乐、哭泣、大声喊叫、击打安全的物品、写情绪日 记、运动、三、了解情绪背后的动机。例如: 图3-1、图3-2: “家暴”, 情绪背后是被爱、被 尊重的需求。图8: “言禁”, 情绪背后是能公平的对话的需求。图11: “纠结”, 情绪背后 是焦虑, 是对未来不可控的恐惧, 也可能是对自我现实能力评价过低所产生的。 


\section{5. 结束语}

关注大学生的情绪问题是大学教育的基础保障。引导大学生积极进行情绪体验、正确面 对情绪问题、创造性的发展大学生情绪管理的办法是提高大学生的情绪智力有效途径。使用 艺术的方法来进行情绪体验及发展情绪智力, 此类研究并不多见, 本文意为抛砖引玉，引发 更多的思考与实践研究，创造性与跨学科的实验是本文的主旨。

\section{References:}

[1]Puguang Gu, Discussion on the Origin of Masks, Literature and Art Studies, pp.136-147.

[2] Shaohua Chen, Psychology of Emotion, pp.3,2011.

[3] Fengjiao Liu, Comprehensive Growth towards a Success-On the development of college students' emotional intelligence based on the importance of emotional intelligence, Journal of shanxi university of finance and economics, vol. 7, pp. 24, 2004.

[4] Wei Liu, Heyong Shen, Xiaoyin Wang, Yun Pan, Research on the Relationship between Adult Attachment, Emotional Experience and Empathy Ability of Psychological Counselors, Chinese journal of clinical psychology, vol. 22, pp. 552, 2014.

[5] Jiuping Cheng, Shiguo Li, Gan Zhang, Application Study of Emotional Experience Based on Stimulus Seeking Motivation in Interactive Design, packaging engineering, vol. 34, NO. 14, 2013. 